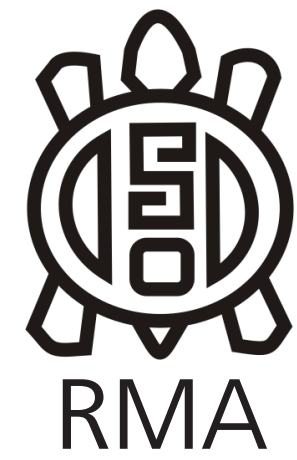

Arqueología

\section{La explotación de pinnípedos en Isla de los Estados: el caso de las ocupaciones de Bahía Crossley I}

\author{
Pinnipeds exploitation in Isla de los Estados: the occupations \\ of Bahía Crossley I
}

María Paz Martinoli*

*CADIC-CONICET, E-mail: mpmartinoli@yahoo.com.ar

\begin{abstract}
Resumen
Las modalidades de explotación de pinnípedos han sido discutidas previamente en la Isla de las Estados a partir del análisis global de los conjuntos provenientes del sitio Bahía Crossley I (2700-1500 años AP). No obstante, dicho yacimiento está conformado por siete capas diferenciadas en función de indicadores crono-estratigráficos. El análisis detallado de cada una de ellas indicó diferencias, principalmente en los perfiles de mortalidad de los otáridos capturados. Mientras los niveles inferiores muestran una mayor presencia de hembras adultas y de individuos menores a un año de $O$. flavescens, en los superiores predominan los machos adultos y subadultos de la misma especie. A ello se le suman variaciones en las estrategias de procesamiento de las carcasas: en los niveles inferiores se ha identificado una mayor variedad de marcas relacionadas con su consumo. Lo dicho tiene al menos dos implicancias. Por un lado, que las ocupaciones pueden corresponder a distintos momentos del año, considerando que los cachorros son indicadores potenciales de capturas realizadas en apostaderos reproductivos. Por otro lado, un aumento relativo en el tamaño de las presas consumidas en los niveles más recientes, lo cual podría relacionarse con algunos procesos de cambio identificados en grupos marítimos del archipiélago de Tierra del Fuego.
\end{abstract}

Palabras clave: Isla de los Estados; Otáridos; Subsistencia; Sitio Bahía Crossley I; Variabilidad.

\begin{abstract}
Pinnipeds exploitation have been previously analyzed in Isla de los Estados based on the global analysis of the assemblages from Bahía Crossley I. However, this deposit is made up of seven layers differentiated according to chrono-stratigraphic indicators. The detailed analysis of each of the levels indicates differences mainly in the mortality profiles of the pinnipeds captured. The lower levels show a greater presence of adult females and individuals younger than one year of $O$. flavescens, while in the upper ones adult males and subadults of the same species predominate. Added to variations in the processing strategies of the carcasses: at lower levels a greater variety of butchery marks related to their consumption has been identified. This has two implications. On the one hand, that the occupations may correspond to different times of the year, considering that the puppies are indicators of captures in rookeries. On the other hand, a relative increase in the size of the prey captured at the most recent levels, which could potentially be related to the processes of change identified in maritime groups of the Tierra del Fuego archipelago.
\end{abstract}

Keywords: Isla de los Estados; Otarids; Subsistence, Bahía Crossley I site; Variability.

La Isla de los Estados se encuentra en el extremo oriental del archipiélago fueguino, separada de la Isla Grande Tierra del Fuego por el Estrecho Le Maire. La distancia entre ambas islas, de alrededor de $30 \mathrm{~km}$, ha llevado a considerar a la primera una isla offshore (Horwitz, 1990). De acuerdo con el modelo paleogeográfico establecido para la región, dicha condición se produjo alrededor de los 12.500 años AP (Rabassa et al., 1992; Ponce, 2009).
Por lo cual, considerando las cronologías conocidas para las ocupaciones humanas, sólo fue posible acceder a la isla a través de la navegación (Horwitz, 1990, 1993).

Las ocupaciones documentadas se corresponden a una serie de yacimientos ubicados principalmente en la bahía Crossley (Chapman, 1987, Horwitz, 1990) y en la bahía Franklin (Zangrando et al., 2017), todas ellas datadas 
en un período comprendido entre los 2700 y los 1500 años AP. A partir del estudio de los conjuntos de Bahía Crossley I (Figura 1), se consideró a la isla como parte de un sistema de asentamiento relacionado con el sector sudeste de Tierra del Fuego y con otras islas que forman parte del archipiélago fueguino (Horwitz, 1990, 1993). Horwitz propuso que las visitas a Isla de los Estados habrían sido intermitentes y se corresponderían con ocupaciones de grupos marítimos del sur de Península Mitre, los que eventualmente ampliaban sus rangos de aprovisionamiento hacia las islas exteriores.

Dada la productividad primaria que poseen los frentes marinos (Acha, Mianzan, Guerrero, Favero y Bava, 2004), durante el verano la isla alberga grandes colonias reproductivas de pinnípedos y aves marinas (Figura 1), los cuales fueron habitualmente consumidos por los grupos con adaptaciones marítimas de la región (Orquera y Piana, 1999, 2009, Schiavini, 1990, Zangrando, 2009). Por lo que, el potencial acceso a los sectores reproductivos de otáridos en momentos de agregación puede haber implicado su explotación (Martinoli, 2017, 2018). En reiteradas oportunidades se ha utilizado la reconstrucción de los perfiles de mortalidad de los pinnípedos como indicadores adecuados para interpretar las posibles estrategias de aprovisionamiento (Borella, 2006, Etnier, 2007, Legoupil, 1989, Lyman, 1989, Orquera y Piana, 1999, Schiavini, 1990, Smith, 1978), dado que tales mamíferos marinos presentan comportamientos relativamente pautados según su especie, su edad y su sexo. Particularmente, las dos especies de otáridos más habituales en la Isla de los Estados (Otaria flavescens y Arctocephalus australis), tienen un régimen social poligínico y su ciclo anual se divide en una etapa reproductiva corta y un período de visitas regulares a áreas costeras. Los apostaderos reproductivos se encuentran mayormente conformados por hembras adultas, cachorros y unos pocos machos adultos dominantes (Vaz Ferreira, 1979, Vaz Ferreira y Vallejo 1981). Por lo cual, en el caso de la captación de presas en tales sectores, se esperarían perfiles de mortalidad con predominio de individuos menores a un año y de hembras en edad reproductiva (Borella, 2006, Etnier, 2007, Lyman, 1989, Schiavini, 1990), aunque también machos adultos en menor proporción (Lyman, 2003).

Estudios previos han establecido algunos aspectos generales relacionados con la explotación de la fauna representada en Bahía Crossley I (Horwitz, 1990, Horwitz y Weissel, 2011, Lanata, Weissel, Caracotche, Belardi, Muñoz y Savanti, 1992). Sin embargo, los autores no realizaron inferencias específicas sobre las posibles modalidades de explotación de pinnípedos, aunque sí se presentan algunos datos relacionados con las unidades anatómicas representadas y abundancia de huellas de procesamiento (Horwitz, 1990, Lanata et al., 1992). Posteriormente, en un trabajo comparativo a escala de la costa sur de Tierra del Fuego (Martinoli, 2017, 2018), se reanalizaron en términos globales los conjuntos zooarqueológicos de pinnípedos. Los restos

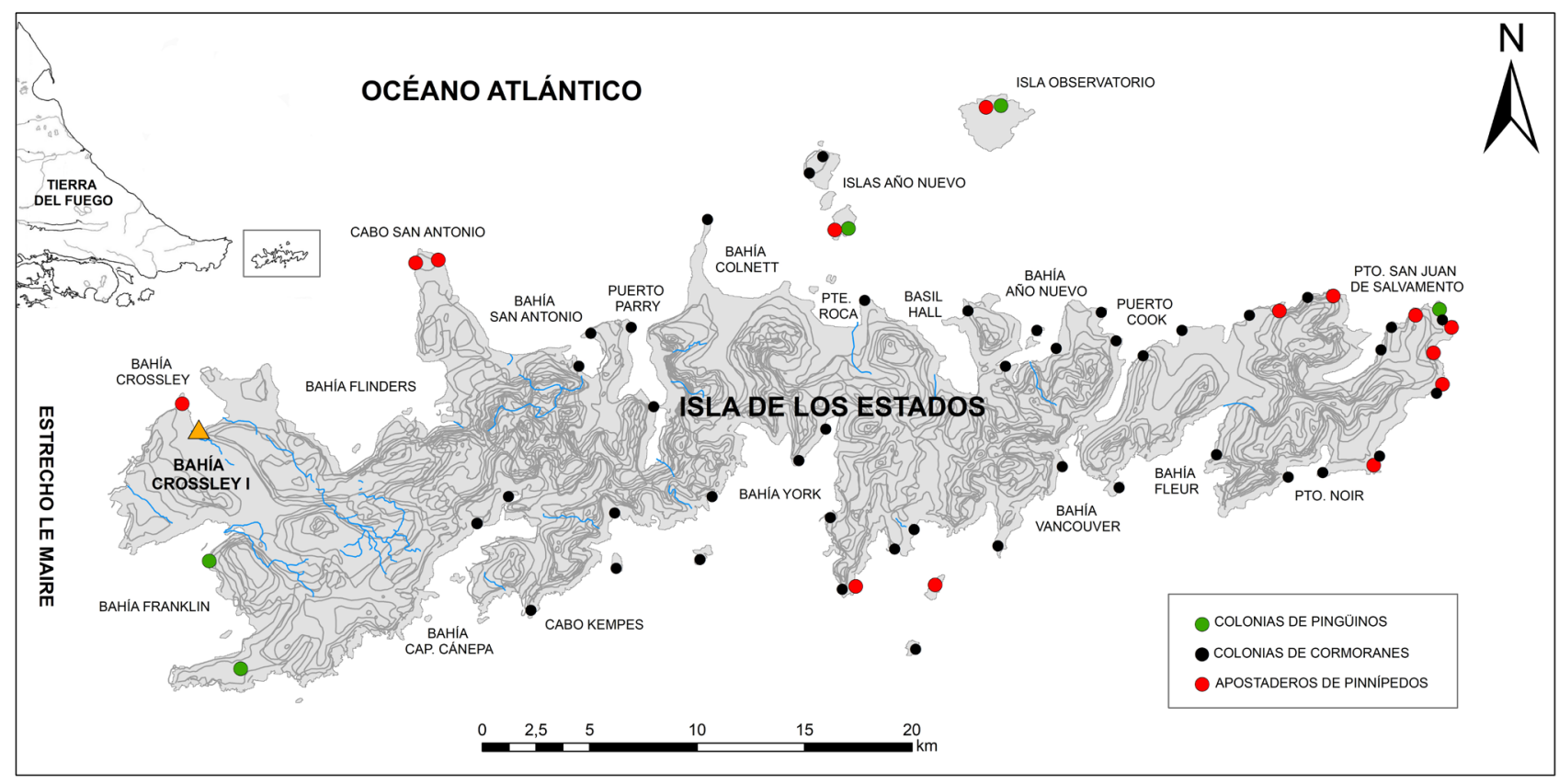

Figura 1. Mapa de Isla de los Estados con ubicación de las colonias de pingüinos y cormoranes, y de los apostaderos de otáridos (Schiavini y Raya Rey, 2001) y del emplazamiento de Bahía Crossley I.

Figure 1. Map of Isla de los Estados with location of penguin and cormorant colonies, and Otariid rockeries (Schiavini and Raya Rey 2001), and Bahía Crossley I site. 
fueron estudiados conjuntamente porque la escala del trabajo era espacialmente muy amplia, además de que el objetivo general se relacionaba con preguntas respecto de pautas de aprovisionamiento, procesamiento y consumo propias de una isla offshore. Lo observado fue, por un lado, el predominio de restos de $O$. flavescens y, por otro lado, la representación de individuos menores a un año de ambas especies, lo cual posiblemente implicó la captura de presas en el ámbito de apostaderos de cría/reproductivos. Asimismo, se encuentra presente la mayoría de las unidades anatómicas, mediante lo cual se presumió que las presas ingresaron completas al sitio. No obstante, respecto de los machos adultos de $O$. flavescens, se observó que las abundancias anatómicas son más variables, lo cual puede implicar que estas presas sí hayan sufrido un transporte diferencial atendiendo a su gran tamaño. Las marcas de procesamiento identificadas indicaron un procesamiento poco integral, principalmente huellas de corte compatibles con desarticulación.

Si bien la conclusión alcanzada a partir del análisis global de los conjuntos de pinnípedos parece indicar la explotación de espacios de cría/reproductivos en verano, Bahía Crossley I es un sitio multicomponente conformado por siete capas intercaladas de arena y tierras conchíferas. Si consideramos la cronología que se obtuvo de estas últimas se destaca que: la capa II -con varias datacionescubre un lapso relativamente continuo entre 1500 y 2300 años AP, la capa IV tiene un fechado de 2500 años AP y la capa VI de 2700 años AP (Chapman, 1987, Horwitz, 1990). A partir de tales dataciones es posible suponer que los depósitos corresponden a momentos de formación diferentes. Incluso en trabajos previos se propusieron distinciones entre las ocupaciones basándose en las variaciones observadas en las frecuencias de restos faunísticos (Horwitz y Weissel, 2011). Como ya se indicó, los otáridos tienen ciclos que implican que su presencia en tierra varía estacionalmente, por lo que diferentes ocupaciones a lo largo del año podrían implicar la puesta en práctica de distintas modalidades de explotación en función del acceso a los recursos (Legoupil, 1989, Lyman, 1989, Smith, 1978). Por lo tanto, es posible esperar variaciones, al menos, en los perfiles de mortalidad. Especialmente si se considera la propuesta de Horwitz (1990) de que las visitas a Isla de los Estados fueron de carácter esporádico.

Sobre la base de lo expuesto, el objetivo del presente trabajo es evaluar posibles variaciones en las estrategias de captura, procesamiento y consumo de pinnípedos implementadas en los distintos momentos de ocupación de Bahía Crossley I. Dicho análisis permitirá, por un lado, la comparación entre los distintos niveles que conforman el sitio; por otro lado, corroborar si los resultados obtenidos del análisis detallado de los conjuntos de pinnípedos indica diferencias respecto de la interpretación realizada a partir del análisis global. Distribución y caracterización de los otáridos del
archipiélago fueguino

Los pinnípedos más habituales y abundantes en el archipiélago fueguino pertenecen a dos especies de la familia Otariidae: los lobos marinos de dos pelos ( $A$. australis) y los lobos marinos de un pelo (O. flavescens) (Bastida y Rodríguez, 2003).

Los $A$. australis se ubican sobre costas rocosas y con cierta exposición al oleaje (Schiavini, 1990, Sielfeld, 1983), motivo por el cual se concentran principalmente en islotes escarpados (Bastida y Rodríguez, 2003, Schiavini, 1990). En Argentina se observa una alta concentración en el sector argentino de Tierra del Fuego (Schiavini y Raya Rey, 2001), donde se destacan los apostaderos reproductivos de Isla de los Estados (4.200 individuos distribuidos en cinco colonias de cría y dos loberías no reproductivas (Figura 1; Crespo et al., 2015, Schiavini y Raya Rey, 2001). Por su parte, la especie $O$. flavescens elige costas con declives suaves y más reparadas, tal es así que su distribución geográfica es continua a lo largo de toda la costa, además de la ocupación de islas e islotes (Schiavini, 1990, Schiavini y Raya Rey, 2001, Sielfeld, 1983). La porción argentina de Tierra del Fuego aloja un total de 26 colonias y apostaderos (Schiavini, Crespo, Szapkievich, 2004). Se han identificado tres importantes zonas de cría: las Islas Becasses (canal Beagle), Península Mitre (v.g. la colonia de Tres Amigos) y la Isla de los Estados (Figura 1).

Estas dos especies de otáridos presentan variaciones en cuanto a los tamaños. El lobo de dos pelos alcanza las siguientes dimensiones promedio): crías entre 3,5 y 5,5 kg; machos adultos: 1,9 m y 159 kg; hembras adultas: 1,4 m y 48,5 kg; estos datos pertenecen a pinnípedos de las Islas Malvinas (Vaz Ferreira, 1979, 1981). Por su parte, los tamaños del lobo de dos pelos son los siguientes (Vaz Ferreira, 1979, Schiavini, 1990): crías entre 10,2 y 14,8 kg.; machos adultos: 2,56 m y 300-340 kg.; hembras adultas: $2 \mathrm{~m}$ y $144 \mathrm{~kg}$.

La temporada de parición de los lobos marinos de dos pelos se da entre los meses de noviembre y diciembre, mientras que la de los lobos marinos de un pelo se produce en los meses de enero y febrero (Schiavini, 1990, Sielfeld, 1983). Durante estos períodos se ha observado el establecimiento de dos tipos distintos de apostaderos: a) de juveniles; y b) de cría (predominio de cachorros, hembras y machos adultos territoriales) (Vaz Ferreira, 1979, Vaz Ferreira y Vallejo, 1981). Fuera del período reproductivo forman loberías de descanso, que pueden coincidir o no con las áreas de reproducción, cuya estructura social presenta cierta variabilidad en la edad y sexo (Vaz Ferreira, 1979, Vaz Ferreira y Vallejo, 1981). En términos generales, los machos adultos no territoriales y los individuos inmaduros se agrupan en asentamientos específicos, pero con una tendencia a permanecer más tiempo en el agua que en tierra (efectúan largos 
desplazamientos en busca de alimentos), mientras que las hembras regresan continuamente a las zonas de cría para amamantar a los cachorros, siendo sus movimientos más restringidos en tiempo y espacio (Vaz Ferreira, 1979, Vaz Ferreira y Vallejo, 1981).

\section{El sitio Bahía Crossley I}

Bahía Crossley I es un conchero estratificado a cielo abierto emplazado en la playa baliza Zaratiegui, actualmente apoya sobre una playa de arena a $12 \mathrm{~m}$ s.n.m. Hacia el sur el sitio se encuentra bordeado por una serie de dunas que forman terrazas de alturas variables y que cubren parcialmente el sitio, por lo que su límite real no se determinó (Horwitz, 1990).

La estratigrafía del sitio fue definida en tres niveles de tierras conchíferas superpuestas (capas II, IV y VI) intercaladas por suelos arenosos (capas I, III, V y VII). La porción norte mostraba una erosión superficial parcial, y la relación estratigráfica no era similar a la del sector sur (Horwitz 1990: 253, figura 12). En total se excavaron once cuadrículas de $1 \times 1 \mathrm{~m}$ que abarcaron distintos sectores del sitio (Horwitz, 1990: 256, figura 15). Las muestras de carbón recuperadas para realizar los fechados (Horwitz y Weissel, 2011: 151, tabla 1) provienen del sondeo realizado en lo que se denominó Sector Alto (Chapman, 1987) y de las cuadrículas excavadas al nivel de la playa actual (Horwitz, 1990).

Las capas I, III y V se interpretaron como hiatos ocupacionales, a pesar de que se hallaron restos óseos y algunos moluscos. Asimismo, la capa VII fue definida como el nivel de base de la ocupación humana inicial (Horwitz y Weissel, 2011). Las capas de tierras conchíferas se consideraron, ya sea como tres eventos aislados de ocupación y/o el agregado de visitas cercanas en el tiempo (Horwitz, 1990). La capa II fue documentada en las once cuadrículas excavadas y las IV y VI aparecen en las cinco cuadrículas orientales, donde no se registró erosión de la superficie.

Con respecto a los artefactos recuperados en Bahía Crossley I, los líticos incluyen 17 raspadores, cinco raederas, un yunque, dos boleadoras, dos cuchillos, un rodado con surco y cinco lascas utilizadas (Horwitz y Weissel, 2011: 153, figura 5). Los distintos artefactos mostraron similares atributos, pero diferencias significativas con relación a la densidad de estos en cada capa. Las ocupaciones más recientes (capas de superficie, I y II) incluían 20 instrumentos. Las capas III, IV y V no contenían materiales líticos, y en las capas VI y VII se recuperaron nueve instrumentos y cuatro lascas. Entre los artefactos óseos se observan punzones sobre hueso de ave, cinceles confeccionados a partir de restos de pinnípedos, puntas de arpón y cuñas elaboradas con huesos de cetáceo (Horwitz y Weissel, 2011: 155, figura 6). Por su parte, los artefactos óseos no mostraron frecuencias de aparición significativamente diferentes, aunque no se hallaron en la capa V.

El análisis de los restos faunísticos hallados en el sondeo del Sector Alto (Caviglia en Chapman, 1987) incluía únicamente los niveles I y II. Del total de los especímenes identificados como aves (NISP=608), el 74\% pertenece a pingüinos magallánicos (Spheniscus magellanicus). Se identificaron también restos óseos de pinnípedos (NISP=24), los que en su mayoría fueron clasificados como $A$. australis. Los conjuntos óseos recuperados posteriormente indican una tendencia similar: las aves marinas (pingüinos) son el taxón predominante, mientras que los pinnípedos representan menos del 10\% en todas las capas (Horwitz, 1990, Horwitz y Weissel, 2011: 158, Lanata et al., 1992). También fueron analizados los restos óseos de cetáceos (NISP=114). Se identificaron vértebras, fragmentos de cráneo y costillas (Borella, 2003, 2004), representando menos del $1 \%$ del NISP total.

Un aspecto que fue resaltado previamente (Horwitz y Weissel, 2011, Lanata et al., 1992), es la representatividad variable de los pingüinos en cada una de las capas que conforman el sitio. Mientras que en algunos niveles representan más del $60 \%$ del NISP total, en otras no superan el 10\% (Horwitz y Weissel, 2011: 158, tabla 4). Dicho fenómeno podría relacionarse tanto con una disponibilidad diferencial de la especie como con la selección de los grupos humanos por factores contextuales (Lanata et al., 1992). Es de destacar que los especímenes óseos de pingüinos se observan más procesados en las capas superiores en concordancia con la mayor presencia de instrumental lítico (Horwitz y Weissel, 2011).

Tanto en el análisis inicial de los restos óseos de pinnípedos (Lanata et al., 1992) como en su re-análisis (Martinoli, 2017,2018 ) fue posible observar que más del 30\% de los especímenes mostraban algún grado de abrasión y elevados niveles de porosidad y blanqueamiento. Los agentes que probablemente actuaron en Bahía Crossley I fueron la arena -matriz dominante en la mayoría de los depósitos- y el agua (Claussen, 1989, Horwitz 1990, Lanata et al., 1992).

\section{Materiales y métodos}

Los restos óseos de pinnípedos analizados en el presente trabajo fueron 1.182. La totalidad de dichos conjuntos corresponden a los materiales recuperados por Victoria Horwitz en las campañas realizadas en 1986 y 1987, alojados en el Museo del Fin del Mundo, Ushuaia, Tierra del Fuego, Argentina.

A los fines de medir la abundancia relativa de las distintas especies y categorías de edad y sexo representadas se han utilizado los indicadores usualmente empleados en los análisis zooarqueológicos: NISP y NMI (Grayson, 
1984, Lyman, 1994). En el presente trabajo fue usado un criterio amplio para el cálculo del NMI que incluye (además de la identificación anatómica y de la lateralidad) la determinación de la especie, la edad y el sexo del individuo (Grayson, 1984, Lyman, 1994). En el caso de aquellos individuos en los que la categoría era coincidente se utilizó un único elemento de igual lateralidad con el fin de no sobrestimar la cantidad de ejemplares presentes en la muestra.

Para la identificación taxonómica se utilizaron rasgos morfológicos del cráneo y del poscráneo (Borella, Vales, Grandi y García, 2018, Cadegán Sepúlveda, 2013, Legoupil, 1989, Pérez García, 2003) y las amplias colecciones de referencia disponibles en el Museo Acatushún y en el CADIC. Entre los primeros consideramos: a) la forma del hueso palatino; b) la forma de la arcada dentaria superior y c) la forma de los maxilares inferiores (Legoupil, 1989). Existen dos trabajos (Pérez García, 2003; Cadegán Sepúlveda, 2013) que presentan un conjunto de caracteres discriminantes entre las dos especies de otáridos mayores a un año (Pérez García, 2003, 2008) en elementos del poscráneo.

La diferenciación es realizada a partir de los huesos de las cinturas de los miembros, del atlas, del axis y del sacro (Pérez García, 2003). Particularmente los huesos pertenecientes a la cintura escapular de $O$. flavescens presentan características que evidencian un mayor rendimiento muscular plasmado en un tamaño comparativamente mayor de las estructuras óseas de los miembros, destacando las zonas de inserciones musculares y articulaciones (Cadegán Sepúlveda, 2013). También fueron considerados los rasgos diagnósticos propuestos para: escápula, húmero, cúbito, escafolunar, fémur, tibia/peroné, calcáneo, astrágalo, pelvis, sacro y atlas (Borella et al., 2018: 193-194). Para las esternebras se tomó en cuenta la observación de diferencias en la forma (más planas en $O$. flavescens) entre ambas especies (Martinoli, 2018).

Para la determinación de las categorías de edad utilizamos el esquema de fusión preliminar epifisaria para el esqueleto poscraneal de otáridos (Borella, Grandi, Vales, Goodall y Crespo, 2013). A su vez, Pérez García (2008) describe algunos rasgos anatómicos que se desarrollan en las distintas etapas del ciclo de desarrollo de los otáridos: a) el lactante (estadio 0 y l); b) los individuos en su segundo año de vida, es decir recién destetados (estadio II); c) los subadultos que ya han superado el segundo año de vida (estadio III); y d) los adultos que han finalizado la etapa de crecimiento (estadio IV). La autora describe específicamente algunas estructuras óseas que se desarrollan luego del primer año de vida, las cuales podrían entonces indicarnos la presencia de cachorros en el registro arqueológico. Las tres categorías de edad utilizadas son: cachorros (individuos menores a un año), juveniles/subadultos (individuos en edad no reproductiva) y adultos (individuos en edad reproductiva).

Para la determinación del sexo se observó la forma de los coxales en su extremo posterior (conformado por el isquion y el pubis) (King, 1983). Asimismo, se consideró el dimorfismo sexual que presentan ambas especies. En el caso de $A$. australis, además se midió el ancho máximo de la corona de los caninos; valores menores/iguales a 8 $\mathrm{mm}$ incumben a hembras, mientras que medidas mayores a machos (Schiavini, 1990: 280, figura 28). Respecto de 0 . flavescens el ancho mandibular presenta diferencias significativas entre machos y hembras, con una media de $26,2 \mathrm{~mm}$ ( $\pm 8,9 \mathrm{~mm}$ ) para los primeros y de 15,6 $\mathrm{mm}$ $( \pm 3,1 \mathrm{~mm})$ para las segundas (Crespo, 1984).

En función de la determinación realizada según los indicadores especificados en el nivel taxonómico, de edad y sexo, se decidió además agrupar a los individuos por tamaño, considerando que los pinnípedos muestran mucha variabilidad entre las distintas categorías y que tal criterio puede ser potencialmente útil para discutir aspectos relacionados con el aporte de estas presas a la dieta, además de cambios en los patrones de subsistencia relacionados con la selección (Etnier 2007). Los ejemplares considerados pequeños incluyen cachorros y hembras subadultas y adultas de $A$. australis ( $\geq 50 \mathrm{~kg}$ ). Los medianos a machos subadultos y adultos de $A$. australis, hembras adultas y subadultas de $O$. flavescens (51-159 $\mathrm{kg}$ ). Los grandes a machos adultos y subadultos de 0 . flavescens $(\leq 160 \mathrm{~kg})$.

En cuanto a los indicadores que describen la diversidad de partes esqueletarias, se trabajó con las unidades MNE, MAU y \%MAU (Grayson, 1984, Lyman, 1994). Se hará referencia de manera discriminada a las abundancias anatómicas sólo en el caso de los restos de o. flavescens macho adulto, dado que su gran tamaño permite diferenciar dicho taxón en todos los elementos que conforman el esqueleto. Para evaluar los perfiles anatómicos, la frecuencia de partes esqueletarias (\%MAU) obtenidas para los restos de pinnípedos fue correlacionada a través del coeficiente de rho de Spearman, tanto con la densitometría ósea de cada unidad anatómica entera (Borella, Gutiérrez, Fodere y Merlo, 2007), como con el índice de utilidad económica (\%MUI) definido para 0 . flavescens (San Román, 2009).

Para analizar la fragmentación de los conjuntos se utilizó la relación NISP/NME (Lyman, 1994). Las modificaciones antrópicas relevadas fueron las fracturas y la ubicación y tipo (corte, machacado y raspado) de las huellas de corte, además de su relación con las actividades que pueden haber dado origen a tales trazas (Binford, 1981, Cartajena y Labarca, 2007, Lyman, 1992, 1994, Muñoz, 1996, $2005,2014)$. Con respecto a las modificaciones de origen natural se documentó el grado de meteorización de los especímenes a través de la propuesta de Behrensmeyer (1978). Usamos tales estadios de modo comparativo: la 
categoría sin meteorización ( $\mathrm{s} / \mathrm{m}$ ) corresponde al estadio 0 , baja incluye a los estadios 1 y 2 , media se refiere a los huesos en estadio 3 y alta describe a los restos en los estadios 4 y 5 .

\section{Resultados}

Los distintos niveles que conforman Bahía Crossley I indican una abundancia variable de restos óseos de pinnípedos (Tabla 1). Las dos capas que muestran una menor representación son la I y la V con un NISP de 17 y 22 , respectivamente. Seguidas por la capa III (NISP=120), la VII $(\mathrm{NISP}=146)$, la II (NISP=149), la IV $(\mathrm{NISP}=270)$ y la VI (NISP=458). Asimismo, al pie de la Tabla 1 se indica la determinación general realizada previamente por Lanata y coautores (1992). Las diferencias halladas posiblemente se relacionen con los criterios utilizados para la identificación de unidades anatómicas.

\section{Perfiles de mortalidad}

En términos generales, es posible observar que en la mayoría de los niveles la especie más abundante es $O$. flavescens, con excepción de las capas I y $\mathrm{V}$, relación que no cambia a lo largo de la secuencia de ocupación del sitio Bahía Crossley I, tener en cuenta los niveles que han sido fechados (Figura 2A).

En cuanto a la representación de los individuos considerando el sexo (Figura 2B), macho es la categoría relativamente más abundante en los niveles I, II, III y IV, y su presencia disminuye levemente en las capas V, VI y VII. Por el contrario, en el caso de las hembras sus porcentajes de representación son moderadamente más elevados en niveles inferiores.

En lo que respecta al perfil etario (Figura 2C), la categoría subadulto es la más representada en la mayoría de los niveles, sin embargo, es posible observar una distinción en su abundancia en términos temporales: en los niveles más antiguos (VI y VII) su presencia relativa es comparativamente menor que lo observado en las capas, II, III y IV. Por su parte, los cachorros son porcentualmente más abundantes en los niveles inferiores, especialmente en el nivel VII, en el cual representan el $50 \%$ de los individuos identificados.

A partir de los métodos propuestos en el acápite anterior, fue posible realizar una asignación específica a categorías de edad, sexo y taxonómicas de manera conjunta (Tabla 2). En la capa I se determinaron dos individuos, ambos de la especie $A$. australis: un macho adulto y uno subadulto. En el nivel II identificamos siete individuos, de los cuales cuatro corresponden a $O$. flavescens y tres a $A$. australis: los machos subadultos de la primera especie son los más abundantes. En la capa III se estableció la presencia de cinco individuos, de los cuales dos corresponden a machos subadultos de $O$. flavescens y uno a un macho adulto de la misma especie y $\operatorname{dos} A$. australis, un individuo menor a un año y un macho subadulto. El nivel IV presentó un $\mathrm{NMI}$ de siete: dos machos adultos, una hembra adulta y dos machos subadultos de $O$. flavescens y dos machos subadultos de $A$. australis. En la capa V, la mayoría de los individuos determinados ( $\mathrm{NMI}=4)$ son de la especie A. australis: una hembra adulta, un macho subadulto y un cachorro de sexo indeterminado. Respecto de $O$. flavescens se identificó a un macho subadulto. El nivel $\mathrm{VI}$ es el que presentó el NMI más elevado (NMI=10), las dos categorías más abundantes son los machos adultos y machos subadultos de 0 . flavescens, sin embargo, la mayoría de las clases de edad y sexo están representadas, con una presencia interesante de hembras e individuos menores a un año. Por último, en la capa VII se determinó un total de cuatro individuos, todos de la especie $O$. flavescens, siendo los menores a un año los más abundantes.

En función de la reconstrucción del perfil de mortalidad completo para cada nivel agrupamos los individuos según rangos de tamaño. Como se observa en la Figura 3, las dimensiones de los otáridos capturados muestran una variación a lo largo de la secuencia de ocupación del sitio Bahía Crossley I. Mientras en los niveles inferiores son más abundantes las presas pequeñas/medianas, en los niveles superiores se encuentran más representados animales grandes. La excepción se observa en la capa I, sin embargo este era el nivel más alterado por procesos erosivos propios de contextos de dunas (Horwitz, 1990).

\section{Perfiles anatómicos}

Los especímenes óseos correspondientes a pinnípedos en las capas I y $\mathrm{V}$ eran muy escasos, por lo cual no fueron incluidos en los cálculos de \%MAU. En los niveles restantes se observa cierta homogeneidad en la frecuencia de las unidades anatómicas. Si consideramos en primer término las capas que corresponden a tierras conchíferas (Figura 4A), en los tres conjuntos está representada la mayoría de las unidades anatómicas, pero con valores de \%MAU relativamente variables. En el nivel II observamos que muchos de los elementos esqueletarios están presentes en porcentajes menores al 50\%, salvo los húmeros (100\%), los atlas (80\%) y los peronés (60\%). En este conjunto hay un predominio del esqueleto apendicular por sobre el axial (Figura 4C). En la capa IV ocurre algo similar, si bien la mayoría de las unidades anatómicas están presentes, sus abundancias no superan el 50\%, con excepción de húmeros (100\%), metacarpianos $(71,4 \%)$ y fémures $(57,1 \%)$. Nuevamente, la tendencia en este nivel es una mayor presencia de elementos del esqueleto apendicular, especialmente del miembro anterior (Figura 4C). Por último, en la capa VI se observa un panorama similar: la mayoría de los elementos están representados, pero en porcentajes menores al 50\%, excepto los atlas (100\%), los fémures $(87,5 \%)$, las esternebras (75\%) y los carpianos (62,5\%). Cabe destacar que en este último 
Tabla 1. NISP y NME de pinnípedos en Bahía Crossley I diferenciado por niveles y valores obtenidos por Lanata y colaboradores (1992).

Table 1. NISP and MNE values of zooarchaeological assemblages of pinnipeds in Bahía Crossley I differentiated by levels compared to the values obtained by Lanata et al. (1992).

\begin{tabular}{|c|c|c|c|c|c|c|c|c|c|c|c|c|c|c|}
\hline \multirow{2}{*}{\begin{tabular}{|l|l} 
Unidades Anatómicas \\
Cabeza
\end{tabular}} & \multicolumn{2}{|c|}{ Capa I } & \multicolumn{2}{|c|}{ Capa II } & \multicolumn{2}{|c|}{ Capa III } & \multicolumn{2}{|c|}{ Capa IV } & \multicolumn{2}{|c|}{ Capa V } & \multicolumn{2}{|c|}{ Capa VI } & \multicolumn{2}{|c|}{ Capa VII } \\
\hline & NISP & NME & NISP & MNE & NISP & NME & NISP & NME & NISP & NME & NISP & NME & NISP & NME \\
\hline Cráneo & 0 & 0 & 1 & 1 & 0 & 0 & 6 & - & 0 & 0 & 13 & - & 9 & - \\
\hline Hioides & 0 & 0 & 1 & 1 & 0 & 0 & 3 & 3 & 0 & 0 & 2 & 2 & 2 & 1 \\
\hline Maxilares & 0 & 0 & 1 & 1 & 0 & 0 & 5 & 3 & 0 & 0 & 6 & 4 & 3 & 1 \\
\hline Caninos & 0 & 0 & 1 & 1 & 1 & 1 & 1 & 1 & 0 & 0 & 3 & 3 & 4 & 4 \\
\hline Premolares & 0 & 0 & 0 & 0 & 0 & 0 & 9 & 9 & 0 & 0 & 4 & 4 & 10 & 10 \\
\hline Incisivos & 0 & 0 & 0 & 0 & 0 & 0 & 4 & 4 & 0 & 0 & 1 & 1 & 3 & 3 \\
\hline Subtotal & 0 & 0 & 4 & 4 & 1 & 1 & 28 & 20 & 0 & 0 & 29 & 14 & 31 & 19 \\
\hline \multicolumn{15}{|l|}{ Esqueleto Axial } \\
\hline Costillas & 6 & 4 & 38 & 19 & 41 & 22 & 51 & 21 & 1 & 1 & 141 & 53 & 25 & 14 \\
\hline Esternebras & 0 & 0 & 3 & 3 & 3 & 3 & 5 & 5 & 1 & 1 & 17 & 17 & 5 & 4 \\
\hline Escápulas & 0 & 0 & 1 & 1 & 2 & 2 & 1 & 1 & 1 & 1 & 6 & 3 & 4 & 2 \\
\hline Atlas & 0 & 0 & 2 & 2 & 0 & 0 & 1 & 1 & 0 & 0 & 5 & 4 & 0 & 0 \\
\hline Axis & 0 & 0 & 0 & 0 & 0 & 0 & 0 & 0 & 0 & 0 & 2 & 2 & 1 & 1 \\
\hline Vértebras Cervicales & 0 & 0 & 4 & 3 & 7 & 7 & 16 & 6 & 1 & 1 & 24 & 7 & 2 & 1 \\
\hline Vértebras Torácicas & 0 & 0 & 18 & 11 & 15 & 9 & 42 & 15 & 1 & 1 & 63 & 23 & 21 & 9 \\
\hline Vértebras Lumbares & 0 & 0 & 6 & 4 & 5 & 4 & 13 & 6 & 0 & 0 & 13 & 6 & 7 & 4 \\
\hline Sacro & 0 & 0 & 2 & 1 & 0 & 0 & 3 & 3 & 0 & 0 & 8 & 3 & 0 & 0 \\
\hline Vértebras Caudales & 0 & 0 & 1 & 1 & 0 & 0 & 0 & 0 & 0 & 0 & 11 & 6 & 1 & 1 \\
\hline Vértebras Indeterminables & 0 & 0 & 5 & 0 & 19 & 8 & 43 & 15 & 1 & 1 & 33 & 12 & 13 & 2 \\
\hline Huesos Pénicos & 0 & 0 & 0 & 0 & 0 & 0 & 2 & 1 & 0 & 0 & 0 & 0 & 0 & 0 \\
\hline Subtotal & 6 & 4 & 80 & 45 & 92 & 55 & 177 & 74 & 6 & 6 & 323 & 136 & 79 & 38 \\
\hline \multicolumn{15}{|l|}{ Miembros Anteriores } \\
\hline Húmeros & 1 & 1 & 8 & 5 & 1 & 1 & 7 & 7 & 3 & 3 & 4 & 3 & 4 & 3 \\
\hline Radios & 2 & 1 & 2 & 2 & 1 & 1 & 2 & 1 & 0 & 0 & 10 & 3 & 0 & 0 \\
\hline Ulnas & 0 & 0 & 1 & 1 & 1 & 1 & 2 & 2 & 0 & 0 & 6 & 3 & 0 & 0 \\
\hline Metacarpianos & 2 & 2 & 8 & 6 & 3 & 3 & 9 & 9 & 5 & 4 & 18 & 17 & 2 & 2 \\
\hline Carpianos & 1 & 1 & 7 & 7 & 2 & 2 & 6 & 6 & 4 & 4 & 13 & 13 & 5 & 5 \\
\hline Falanges Ants. Primeras I & 0 & 0 & 3 & 2 & 1 & 1 & 2 & 1 & 0 & 0 & 2 & 2 & 0 & 0 \\
\hline Falanges Ants. Indet. & 2 & 2 & 9 & 6 & 2 & 2 & 3 & 3 & 1 & 1 & 6 & 5 & 6 & 4 \\
\hline Subtotal & 8 & 7 & 38 & 29 & 11 & 11 & 31 & 29 & 13 & 12 & 59 & 46 & 17 & 14 \\
\hline
\end{tabular}

conjunto las unidades anatómicas del esqueleto axial son más abundantes que en los tardíos (Figura 4C).

En los niveles de arena III y VII (Figura 4B), lo que se observa a partir del análisis de las abundancias anatómicas es una tendencia general similar a la de los conjuntos presentados previamente: la mayoría de las unidades anatómicas están representadas en porcentajes generales menores al 50\%, salvo las vértebras cervicales (100\%), las esternebras (100\%), los húmeros (75\%) y las pelvis (75\%). Manteniendo la relación general de mayor abundancia de los elementos del esqueleto apendicular (Figura 4C).

En los niveles II, III, IV y VI hemos identificado restos correspondientes a machos adultos de $O$. flavescens, los cuales por su gran tamaño pudieron ser analizados por separado del resto de los elementos, aunque en términos de NISP. Lo que se observa es que las carcasas correspondientes a dicha categoría se encuentran relativamente incompletas y representadas por unos pocos elementos tanto del esqueleto axial como del apendicular (Figura 4D).

Evaluamos las representaciones anatómicas generales en función de los valores de densidad mineral ósea de la especie O. flavescens (Borella et al., 2007), ya que es el taxón más abundante, para indagar sobre la posible preservación diferencial de elementos. En ningún caso se corroboró una relación de co-dependencia, ni tampoco se obtuvieron valores de $p$ estadísticamente significativos 

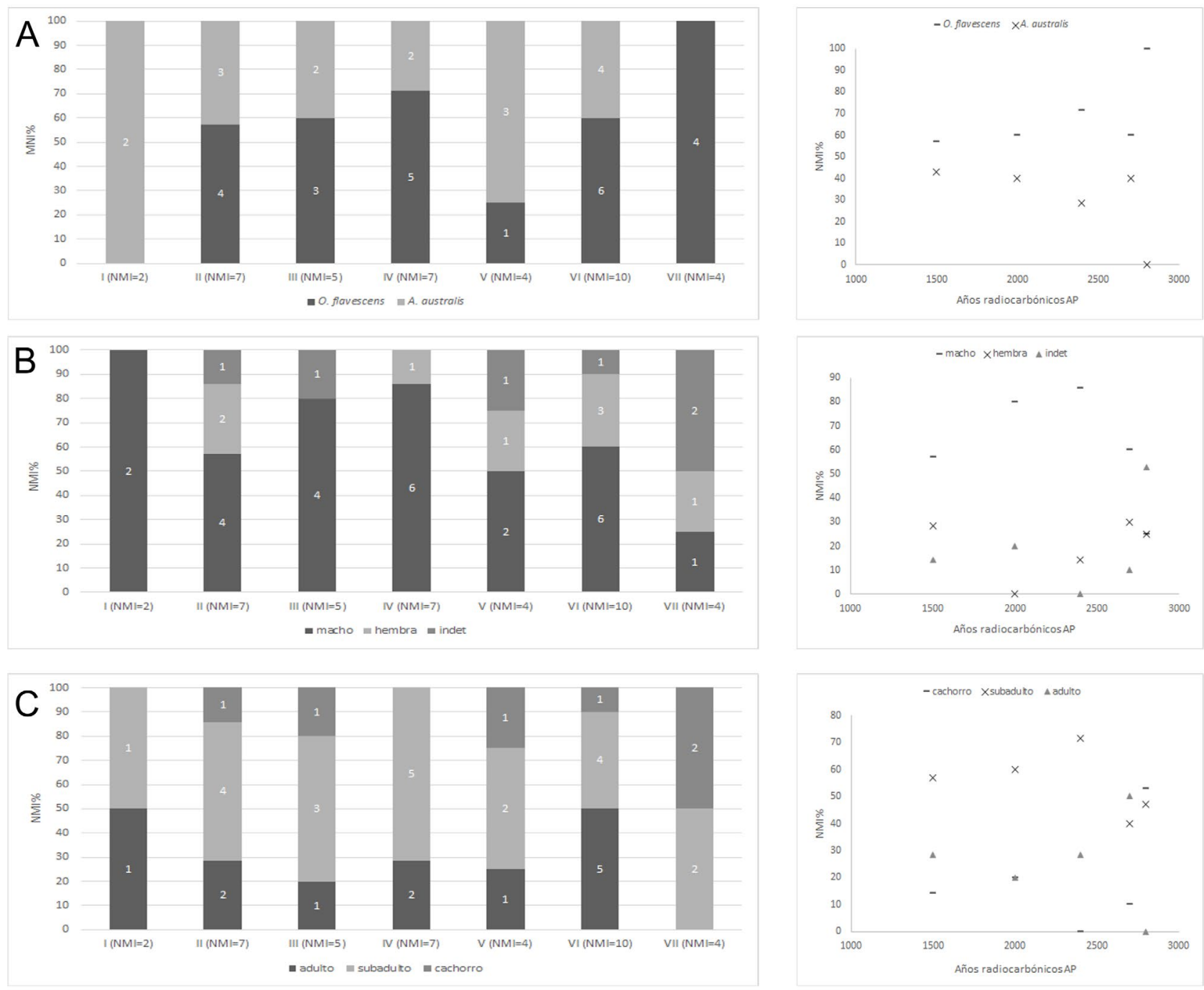

Figura 2. Perfiles de mortalidad de los conjuntos de otáridos de Bahía Crossley I diferenciado por niveles estratigráficos y sus variaciones a lo largo de la secuencia de ocupación del sitio, según: A) especie; B) sexo; y C) categoría etaria.

Figure 2. Otariid mortality profiles in Bahía Crossley I by stratigraphic units, and their variations throughout the archaeological sequence according to: A) species; B) sex; and C) age category.

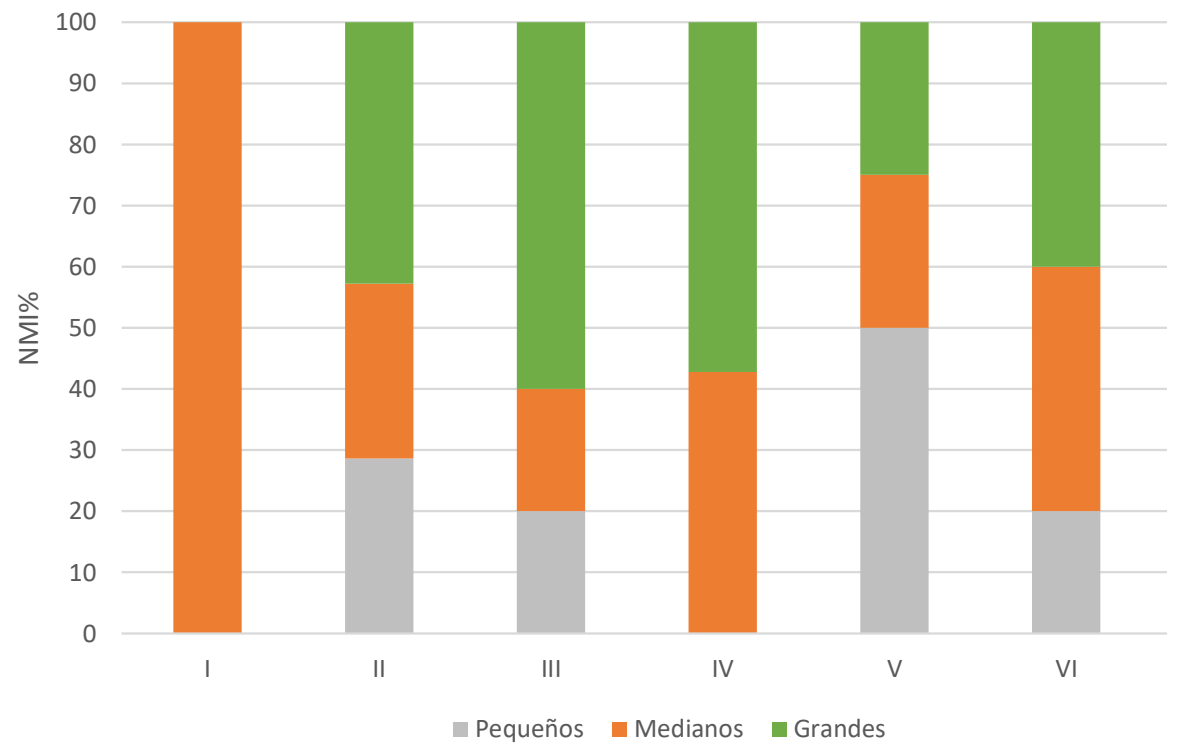

ISSN 1852-060X (impreso) / ISSN 1852-4826 (electrónico)
Figura 3. Perfil de tamaño de los otáridos identificados en Bahía Crossley I, diferenciado por nivel estratigráfico.

Figure 3. Otariid size profiles in Bahía Crossley I by stratigraphic units. 
Tabla 2. Determinación taxonómica, de sexo y edad de los otáridos presentes en cada uno de los niveles que conforman el sitio Bahía Crossley I.

Table 2. Otariid taxonomic determination, sex and age in Bahía Crossley I.

\begin{tabular}{|c|c|c|c|c|c|c|c|}
\hline Capa & Unidades Anatómicas & Lat. & Edad según fusión & $\begin{array}{l}\text { Edad según desarrollo } \\
\text { de estructuras óseas }\end{array}$ & Edad & $\begin{array}{c}\text { Especie (rasgos } \\
\text { morfológicos/tamaño) }\end{array}$ & Sexo \\
\hline \multirow{2}{*}{1} & Húmero & Izq. & más de 11 años & estadio IV & adulto & A. australis & macho \\
\hline & Radio & Izq. & menos de 7 años & estadio III & subadulto & A. australis & macho \\
\hline \multirow{7}{*}{ II } & \multirow{2}{*}{ Fémures } & Der. & menos de 7 años & estadio III & subadulto & A. australis & macho \\
\hline & & Der. & menos de 8 años & estadio III & subadulto & A. australis & hembra \\
\hline & \multirow{2}{*}{ Húmeros } & Izq. & más de 11 años & estadio IV & adulto & O. flavescens & macho \\
\hline & & Der. & menos de 6 años & estadio III & subadulto & O. flavescens & macho \\
\hline & Radio & Izq. & menos de 7 años & estadio I & cachorro & A. australis & - \\
\hline & Esternebra I & a & - & - & adulto & O. flavescens & hembra \\
\hline & Metacarpiano I & Der. & sin osificar & - & juvenil & O. flavescens & macho \\
\hline \multirow{6}{*}{ III } & Fémur & Izq. & menos de 7 años & estadio III & subadulto & A. australis & macho \\
\hline & Radio & Izq. & menos de 8 años & estadio III & subadulto & A. australis & macho \\
\hline & Húmero & Izq. & más de 11 años & estadio IV & adulto & O. flavescens & macho \\
\hline & Metacarpiano III & Der. & sin osificar & - & juvenil & O. flavescens & macho \\
\hline & Tibia & Izq. & menos de 10 años & estadio III & subadulto & O. flavescens & macho \\
\hline & Atlas & a & menos de 1 año & estadio I & cachorro & A. australis & - \\
\hline \multirow{9}{*}{ IV } & \multirow{5}{*}{ Húmeros } & Izq. & menos de 6 años & estadio III & juvenil & A. australis & macho \\
\hline & & Izq. & menos de 6 años & estadio III & subadulto & O. flavescens & macho \\
\hline & & Der. & menos de 6 años & estadio III & subadulto & O. flavescens & macho \\
\hline & & Der. & menos de 6 años & estadio III & subadulto & O. flavescens & macho \\
\hline & & Der. & menos de 5 años & estadio III & subadulto & O. flavescens & hembra \\
\hline & Ulna & Izq. & menos de 8 años & estadio III & subadulto & A. australis & macho \\
\hline & \multirow{3}{*}{ Fémures } & Izq. & más de 11 años & estadio IV & adulto & O. flavescens & macho \\
\hline & & Izq. & más de 11 años & estadio IV & adulto & O. flavescens & macho \\
\hline & & Der. & más de 11 años & estadio IV & adulto & O. flavescens & macho \\
\hline \multirow{4}{*}{ V } & Húmero & Izq. & más de 8 años & estadio IV & adulto & A. australis & hembra \\
\hline & Atlas & $\mathrm{a}$ & menos de 7 años & estadio III & subadulto & O. flavescens & macho \\
\hline & Calcáneo & Izq. & - & estadio III & subadulto & A. australis & - \\
\hline & Atlas & a & menos de 1 año & estadio I & cachorro & A. australis & - \\
\hline \multirow{11}{*}{ VI } & Húmero & Izq. & menos de 5 años & estadio III & subadulto & O. flavescens & hembra \\
\hline & \multirow{2}{*}{ Radios } & Der. & menos de 7 años & estadio III & subadulto & O. flavescens & macho \\
\hline & & Izq. & menos de 7 años & estadio I & cachorro & A. australis & - \\
\hline & \multirow{3}{*}{ Fémures } & Izq. & menos de 7 años & estadio I & cachorro & A. australis & - \\
\hline & & Der. & más de 10 años & estadio IV & adulto & O. flavescens & hembra \\
\hline & & Der. & más de 8 años & estadio IV & adulto & A. australis & hembra \\
\hline & \multirow{4}{*}{ Escafolunares } & Der. & - & estadio IV & adulto & O. flavescens & macho \\
\hline & & Der. & - & estadio IV & adulto & O. flavescens & macho \\
\hline & & Der. & - & estadio IV & adulto & A. australis & macho \\
\hline & & Der. & - & estadio II & juvenil & O. flavescens & macho \\
\hline & Maxilar Inferior & Der. & - & - & subadulto & A. australis & macho \\
\hline \multirow{4}{*}{$\mathrm{VI}$} & Fémur & Izq. & menos de 10 años & estadio III & subadulto & O. flavescens & macho \\
\hline & Escápula & Der. & menos de 5 años & estadio III & subadulto & O. flavescens & hembra \\
\hline & \multirow{2}{*}{ Húmeros } & Izq. & menos de 6 años & estadio I & cachorro & O. flavescens & - \\
\hline & & Izq. & menos de 6 años & estadio I & cachorro & O. flavescens & - \\
\hline
\end{tabular}

entre el \%MAU y la densidad mineral ósea (Capa II: $r_{s}=-$ 0,1; $p>0,05$, Capa III: $r_{s}=-0,1 ; p>0,05$, Capa IV: $r_{s}=0,1$; $p>0,05$, Capa VI: $r_{s}=0,01 ; p>0,05$, Capa VII: $r_{s}=-0,1$; $p>0,05)$.

En lo que respecta al posible ingreso diferencial de porciones anatómicas al área residencial en función de sus valores de utilidad económica, realizamos un análisis de correlación entre el \%MAU de cada nivel y los valores de \%MUI para O. flavescens (San Román, 2009). En ningún caso los resultados indicaron una co-dependencia entre dichas variables. Sin embargo, las capas III y VII revelaron una leve tendencia a la mayor representación de elementos con una utilidad económica entre moderada 

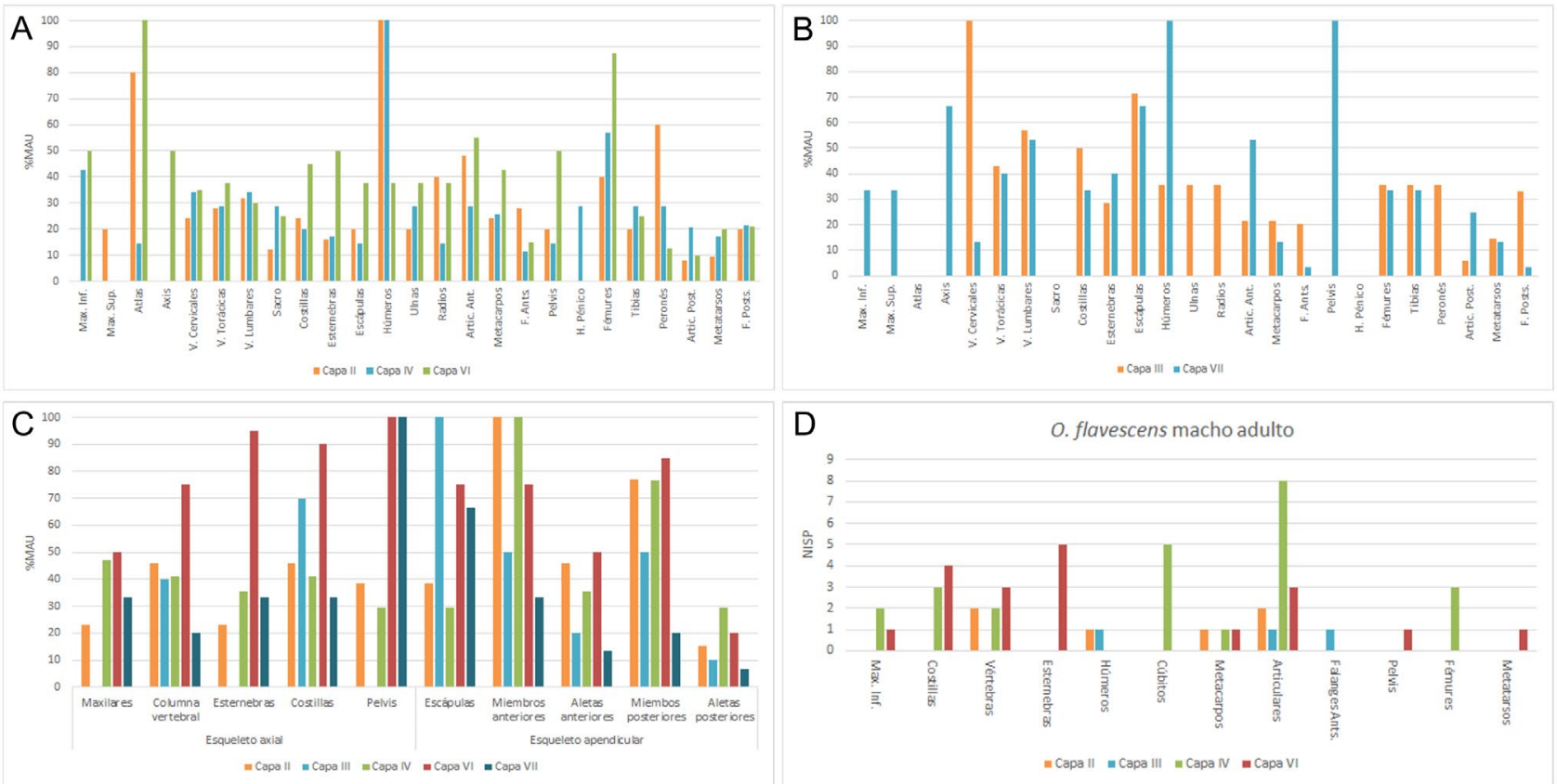

Figura 4. Perfiles anatómicos de los conjuntos de pinnípedos recuperados en Bahía Crossley I. A) \%MAU de los niveles de tierras conchíferas (capas II, IV y VI); B) \%MAU de los niveles de arena (capas III y VII); C) \%MAU diferenciado por porciones anatómicas de las capas II, III, IV, VI y VII; y D) \%MAU correspondiente a machos adultos de $O$. flavescens.

Figure 4. Otariid anatomical profiles in Bahía Crossley I. A)\% MAU values in layers II, IV and VI (shell midden units); B) \%MAU values in layers III and VII (sandy units); C) \%MAU values differentiated by anatomical portions in layers II, III, IV, VI and VII; and D) \%MAU values for adult males of $O$. flavescens.

y alta (Unbiased Strategy, sensu Binford, 1978), aunque el resultado de la correlación no es estadísticamente significativo (Capa II: $r_{s}=0,14 ; p>0,05$, Capa III: $r_{s}=-0,5$; $p=0,07$, Capa IV: $r_{s}=-0,1 ; p>0,05$, Capa VI: $r_{s}=0,2 ; p>0,05$, Capa VII: $\left.r_{s}=-0,4 ; p>0,05\right)$.

\section{Modificaciones óseas}

En términos globales, todas las capas muestran un bajo nivel de fragmentación, medido en términos del cociente entre NISP/NME: en ningún caso dicha relación supera el valor 2, es decir que, en el caso de los niveles con más fragmentación, dos especímenes corresponden a un elemento anatómico. Las dos capas que muestran valores más bajos son la I $(1,2)$ y la $V(1,1)$, mientras la $\mathrm{VI}$ es la que indica el más elevado $(1,9)$. Las fracturas de origen natural y aquellas acaecidas en el proceso de excavación y/o en el posterior acarreo y análisis de los materiales son las más habituales. Por su parte, la incidencia de fracturas intencionales es ínfima, en la capa IV fue hallado un cúbito con un surco perimetral con el que se separó la diáfisis medial (Martinoli 2018: 404, figura 9.5): esto es compatible con un desecho de confección de un cincel (sensu Orquera y Piana 1999), similares a los descriptos para momentos tempranos de la secuencia de ocupación de la porción central del canal Beagle.

Los niveles de meteorización identificados en Bahía
Crossley I son relativamente bajos, sólo se han identificado los estadios 1 y 2 (Behrensmeyer, 1978). Incluso en la mayoría de las capas más del $50 \%$ de los especímenes óseos se observan en estadio 0 (Figura 5).

\section{Marcas de procesamiento}

Al igual que en los trabajos publicados previamente (Horwitz, 1990, Horwitz y Weissel, 2011, Lanata et al., 1992), no hemos hallado ninguna huella de procesamiento en los conjuntos correspondientes a las capas I y $\mathrm{V}$, pero sí en los otros niveles que conforman el sitio, aunque en porcentajes variables, siendo los restos óseos de las capas III y IV los más afectados por trazas relacionadas con su consumo (Figura 6A).

La mayoría de las huellas de procesamiento identificadas en todos los niveles que conforman el sitio Bahía Crossley I corresponden a marcas de corte superficiales que afectan en mayor proporción a los restos óseos de 0 . flavescens (Figura 6B), los que de todos modos son los más abundantes en el registro zooarqueológico aquí estudiado.

Si observamos en detalle las variables relevadas sobre las características y ubicación de las marcas de procesamiento, es posible describir algunas diferencias entre las distintas capas. Mientras en los niveles II y IV la 
mayor incidencia de huellas ocurre en los elementos del esqueleto apendicular, en el resto de las capas lo hacen en el esqueleto axial (Figura 6C). Un punto interesante a destacar es que en términos generales la porción mejor representada es la apendicular, sin embargo la mayoría de las trazas se concentran en el sector axial, lo que indicaría actividades pautadas y sistemáticas respecto del procesamiento de los pinnípedos (Muñoz, 2014).

Si nos focalizamos en el porcentaje de marcas según la porción esqueletaria, la incidencia de huellas es equivalente entre los distintos niveles, salvo el miembro anterior en la capa VI y las costillas en el nivel II (Figura 6D). De todos modos, las tendencias observadas son muy similares, lo que posiblemente se relaciona con la propia anatomía del animal y los gestos para su procesamiento (Lyman, 1992, Muñoz, 2014).

En lo que respecta específicamente a las actividades que pudieron dar origen a las huellas de identificadas, es posible observar algunas sutiles diferencias entre los niveles (Figura 6F). En la capa II todas las trazas identificadas corresponden a marcas de corte superficiales, en su mayoría transversales al eje del hueso. Las huellas de procesamiento observadas en la diáfisis proximal del húmero posiblemente se relacionen con actividades de desarticulación, al igual que las marcas en las vértebras (Lyman, 1992). Las relevadas en las falanges y en un metacarpo corresponderían a procedimientos de cuereo (Cartajena y Labarca, 2007). Los especímenes óseos de pinnípedos de la capa III también muestran únicamente marcas superficiales de corte, las cuales se presentan mayormente agrupadas y con orientaciones transversales. El origen de estas marcas fueron probablemente actividades de desarticulación (trazas en porciones proximales de costillas, de huesos largos y procesos transversos de vértebras) (Lyman, 1992), de descarne (diáfisis mediales de huesos largos) y de cuereo (marcas en falanges distales y tibias) (Cartajena y Labarca, 2007). Las trazas identificadas en los especímenes de la capa IV son todas marcas de corte superficiales y afectan al 8,9\% (NISP=25) de los restos óseos. Este es el nivel estratigráfico que presenta un mayor porcentaje de rastros de procesamiento en comparación con los otros conjuntos óseos que están incluidos en el sitio Bahía Crossley I, siendo que en esta capa todos los individuos identificados corresponden a animales de tamaño mediano y grande (Figura 6E). Las marcas de corte observadas en la porción distal del cuerpo de un maxilar inferior en sentido oblicuo, así como las presentes en los extremos de las diáfisis de metapodianos en sentido transversal al eje del hueso, son compatibles con la actividad de cuereo del animal (Cartajena y Labarca, 2007).

En cuanto a las huellas relacionables con la desarticulación, es posible enumerar: las marcas sobre diáfisis proximales de costillas, en las apófisis de vértebras y en los extremos distales y proximales de huesos largos (Figura 6H) y metapodianos. Por último, se observan trazas de descarne en cuerpos vertebrales (Figura 6G) y en diáfisis mediales de los huesos largos. Las marcas de corte identificadas en la capa VI indican la realización de todas las actividades de procesamiento: desde el cuereo, pasando por la desarticulación y finalmente el descarne de las porciones para su consumo. La primera actividad quedó plasmada en las trazas observadas sobre la porción distal del cuerpo de tres maxilares inferiores en sus caras externas y laterales (Cartajena y Labarca, 2007). En el caso de la desarticulación (Lyman, 1992) hemos hallado marcas de corte sobre las diáfisis proximales de varias costillas, en las apófisis y procesos transversos de vértebras, trazas en sentido transversal sobre la cara lateral de carpianos, huellas en la epífisis distal de un metatarsiano y marcas sobre las diáfisis proximales de tres fémures (Figura 6l). Por último, las huellas relacionadas con el descarne son las presentes en diáfisis mediales de costillas, sobre los cuerpos vertebrales (Figura 6J), en esternebras y sobre la escápula (Cartajena y Labarca, 2007). El último de los niveles que conforman el sitio Bahía Crossley I (capa VII) presenta únicamente marcas de corte superficiales, la mayoría con orientación transversal. Se observaron trazas sobre la porción distal de un maxilar inferior, lo cual podría ser indicativo del cuereo del animal (Cartajena y Labarca, 2007). La ubicación y orientación de las otras huellas de procesamiento identificadas son compatibles con la actividad de desarticulación: diáfisis proximal de

Perfil de meteorización

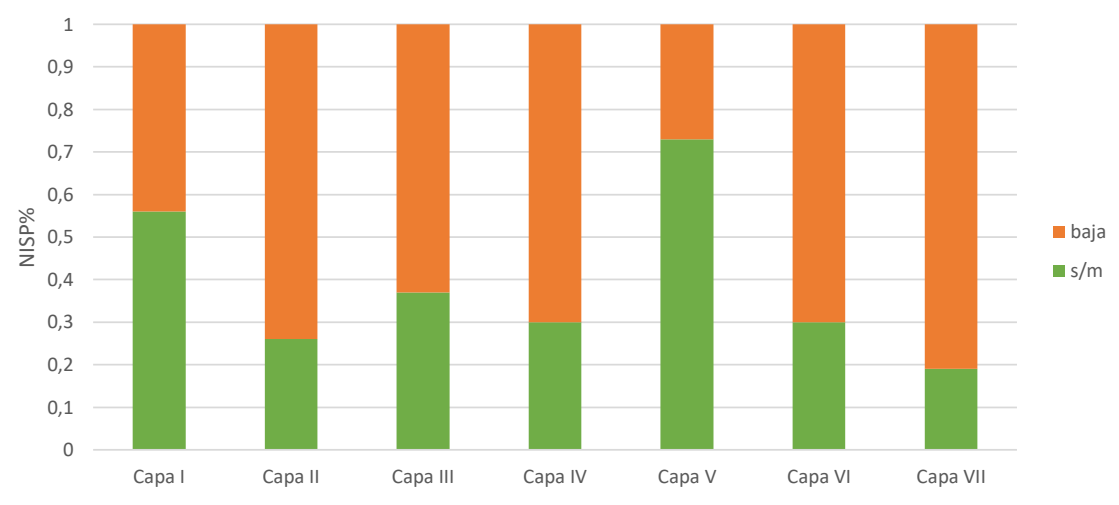

Figura 5. Perfil de meteorización de los otáridos provenientes de Bahía Crossley I, diferenciado por niveles estratigráficos.

Figure 5. Weathering stages for Otariid bones in Bahía Crossley I by stratigraphic units. 

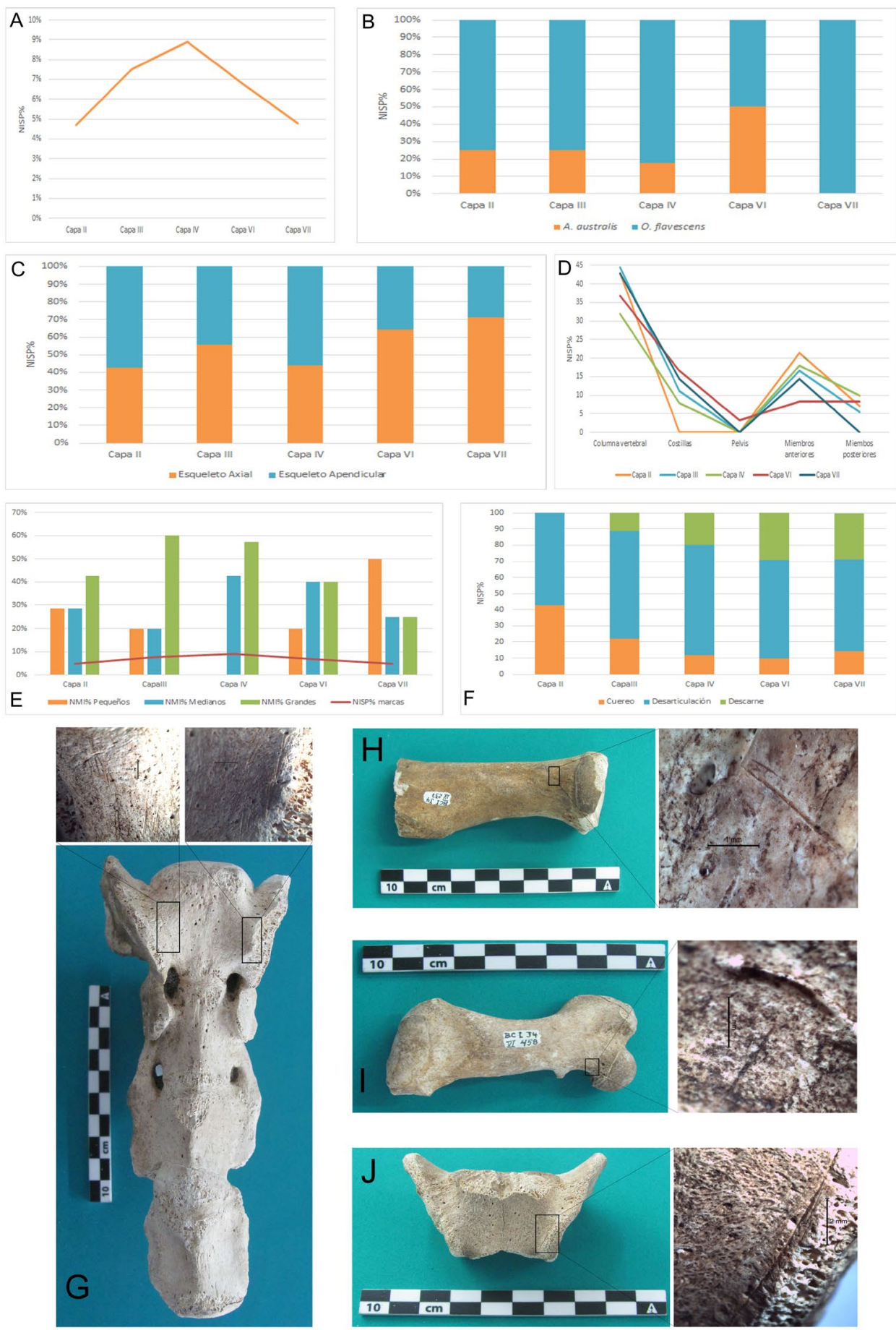

Figura 6. Detalle de las huellas de procesamiento sobre restos de otáridos relevadas en Bahía Crossley I. A) Especímenes con huellas de procesamiento diferenciado por niveles estratigráficos; B) especímenes con huellas de procesamiento según especie diferenciado por niveles estratigráficos; C) distribución de las huellas de procesamiento entre el esqueleto axial y el apendicular; D) distribución de las huellas de procesamiento según porción esqueletaria; E) porcentaje de especímenes con huellas de procesamiento en relación con el tamaño de las presas identificadas en cada nivel estratigráfico; $\mathbf{F}$ ) actividad de procesamiento diferenciada por capa; G) sacro (capa IV) con trazas de descarne; H) radio (capa IV) con trazas de desarticulación; I) fémur (capa VI) con trazas de desarticulación; J) sacro (capa VI) con trazas de descarne.

Figure 6. Otariid processing marks in Bahía Crossley I. A) Specimens with processing marks by stratigraphic levels; B) specimens with processing marks according to species by stratigraphic levels; C) distribution of the processing marks between the axial and the appendicular skeleton; D) distribution of processing marks according to skeletal portion; E) percentage of specimens with processing traces in relation to prey size by stratigraphic level; F) processing activity by layer; G) sacrum (layer IV) with filleting marks; H) radius (layer IV) with disarticulation marks; I) femur (layer VI) with disarticulation marks; J) sacrum (layer VI) with filleting marks. 
una costilla, apófisis y procesos transversos de vértebras, diáfisis distal de un húmero y cuerpo de un carpiano. En el caso del descarne las huellas se ubican en los cuerpos vertebrales.

\section{Discusión}

En publicaciones previas, Horwitz (Horwitz, 1990; Horwitz y Weissel, 2011) propuso que los conjuntos recuperados en los niveles I, III y $\mathrm{V}$ tenían un origen no relacionado directamente con las ocupaciones antrópicas del sitio Bahía Crossley I. Esta interpretación se basó sobre la ausencia de marcas culturales relacionadas con el procesamiento y la representación relativa de las faunas que conforman tales conjuntos (Horwitz y Weissel, 2011). A partir del re-análisis detallado de los restos de pinnípedos fue posible confirmar la ausencia de trazas en los restos óseos de las capas I y V; sin embargo, en el nivel III identificamos un porcentaje elevado de elementos afectados por marcas de origen cultural relacionadas con su aprovechamiento. Por lo antes dicho, coincidimos con la interpretación realizada previamente sobre los niveles I y V; no obstante, consideramos que la capa III puede corresponder (de manera similar que en el nivel VII) al piso de ocupación de la capa de tierra conchífera inmediatamente superior (nivel II).

\section{¿Variabilidad en las modalidades de explotación de} pinnípedos?

Una de las propuestas que guía este trabajo es la posibilidad de identificar diferencias en las estrategias de aprovisionamiento, procesamiento y consumo de pinnípedos entre los distintos niveles que conforman el sitio Bahía Crossley I.

Si nos centramos exclusivamente en la observación de las representaciones taxonómicas de aquellos niveles que consideramos sin duda de origen antrópico, la especie más abundante en todos ellos es $O$. flavescens. Incluso en la capa VII sólo han sido identificados individuos de dicho taxón. Si, por otro lado, consideramos las categorías de edad y sexo representadas en cada uno de dichos niveles, partiendo del hecho de que ambas especies presentan en general comportamientos reproductivos similares, es posible observar algunas variaciones. En primer lugar, los machos juveniles/subadultos se encuentran representados en porcentajes relativamente elevados en los niveles II, III y IV, pero su presencia es comparativamente más baja en las capas más antiguas (VI y VII). En segundo lugar, los machos adultos se observan menos representados en los niveles II y III, son más abundantes en el IV y VI y se encuentran ausentes en la capa VII. En tercer lugar, las hembras juveniles/subadultas y adultas se presentan en general en porcentajes bajos, aunque en el nivel VII las primeras son relativamente más abundantes en términos comparativos. Por último, los individuos menores a un año predominan claramente en la capa VII, pero son poco abundantes en los demás niveles. Por lo antes explicitado, los dos aspectos que es posible resaltar son: a) en la capa VII el predominio de individuos menores a un año y de hembras podría ser un indicador de la explotación de apostaderos reproductivos en época estival; y b) la menor presencia relativa de individuos juveniles/subadultos machos en las capas VI y VII, siendo que su abundancia en los conjuntos zooarqueológicos de pinnípedos está tradicionalmente asociada a la explotación de animales aislados fuera del período reproductivo (Lyman, 1989,

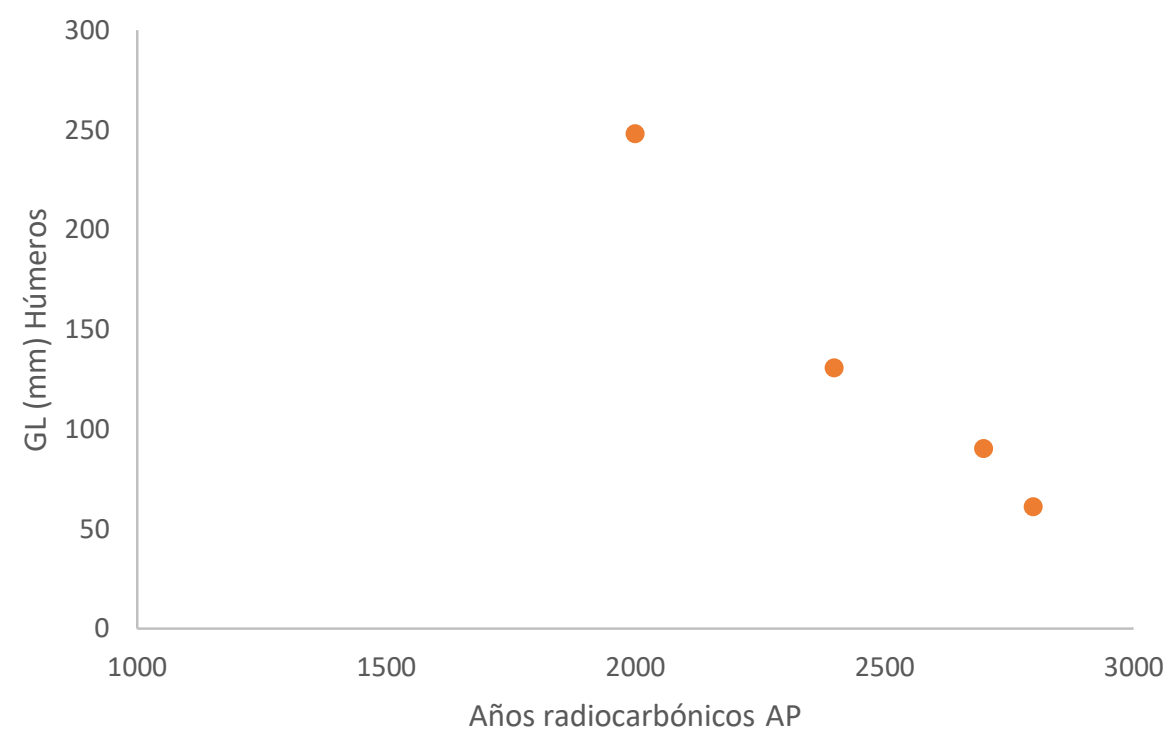

Figura 7. Largos totales (GL, L’Heureux y Borella, 2011) de las diáfisis de los húmeros enteros recuperados en Bahía Crossley I.

Figure 7. Total lengths of humerus diaphysis (GL, L'Heureux and Borella, 2011) in Bahía Crossley I. 
Orquera y Piana, 1999, Schiavini, 1990). Por lo tanto, los perfiles de mortalidad relevados en ambos niveles inferiores podrían ser compatibles con la captura de animales en momentos reproductivos y/o inmediatamente posteriores, incluso la representación moderada de machos adultos puede responder al aprovechamiento eventual de machos dominantes (Lyman, 2003). En el caso de las capas superiores, la baja presencia de individuos menores a un año y el aumento en la presencia de juveniles/subadultos podría ser un indicador de la captura de animales aislados y/o congregados en espacios no reproductivos en distintos momentos del año.

Por su parte, si observamos el tamaño de las presas capturadas a lo largo del tiempo, es posible resaltar que en las capas inferiores las dimensiones promedio de los animales son mayoritariamente pequeño/mediano, mientras que en las capas superiores son más abundantes los pinnípedos grandes. Cabe recordar que la mayoría de los individuos juveniles/subadultos representados en los niveles más recientes corresponden a la especie $O$. flavescens, presas que al alcanzar el $80 \%$ de su crecimiento total pueden sobrepasar los $180 \mathrm{~kg}$. En función de esta observación, consideramos comparativamente los largos totales (GL, L'Heureux y Borella 2011) de los húmeros no fusionados recuperados en los distintos niveles. Como es posible observar en la Figura 7, el tamaño de los subadultos capturados aumentó a lo largo del tiempo. Por lo tanto, la tendencia que parece delinearse a partir de estas observaciones es la selección de presas de mayores dimensiones en las capas superiores del sitio Bahía Crossley I.

En lo que respecta a los perfiles anatómicos reconstruidos a partir de los valores de \%MAU, no hemos observado una tendencia que se manifieste temporalmente. En todos los niveles de origen antrópico se observó la presencia de la mayoría de las unidades anatómicas, pero en porcentajes generales menores al 50\%, salvo algunas excepciones. En cuanto a los elementos esqueletarios correspondientes a machos adultos de $O$. flavescens, es posible observar carcasas relativamente incompletas. No obstante, tampoco en este caso se observan variaciones temporales entre los distintos momentos de ocupación. Es importante remarcar que no hemos encontrado una co-dependencia entre las abundancias anatómicas y los valores de densidad mineral ósea, por lo cual no es posible considerar a dicho factor como condicionante de la estructura del conjunto zooarqueológico.

Por su parte, los análisis de interdependencia entre los valores de \%MAU y los valores de utilidad económica, en ningún caso arrojaron resultados de algún tipo de correlación; sin embargo, en los niveles III y VII se observa una leve tendencia a la mayor presencia de porciones de alto y moderado rendimiento. Asimismo, especialmente en los niveles inferiores se hallaron algunas porciones esqueletarias de bajo rendimiento económico como las aletas en posición articulada (Horwitz y Weissel, 2011: 159), lo cual denota que tales secciones no fueron aprovechadas, sino directamente descartadas. Es necesario recordar que la excavación del sitio Bahía Crossley I, si bien cubrió una superficie amplia, fue realizada a partir de cuadros de $1 \mathrm{~m}^{2}$ en distintos sectores del yacimiento. Por lo cual, consideramos que la aplicación irrestricta de modelos de transporte puede llevar a una mala interpretación de los perfiles anatómicos, en tanto dicha información debe ser usada de manera orientativa respecto de posibles pautas de aprovechamiento de las carcasas.

En cuanto a las marcas de procesamiento relevadas, no se observaron variaciones en su frecuencia en términos temporales, de hecho, los dos niveles que indicaron la incidencia más baja de trazas de corte fueron el II y el VII, es decir los dos extremos de la secuencia del sitio. Aunque sí fue posible relacionar la mayor incidencia de huellas de procesamiento con el tamaño de los animales capturados. En cuanto a las características de las modificaciones óseas, se observaron algunas pequeñas diferencias entre los niveles que conforman Bahía Crossley I. Si bien en términos generales los patrones indican la puesta en práctica de todas las actividades de procesamiento y, por lo tanto, la posición terminal de los restos óseos en la cadena de consumo, en las capas superiores se observa un énfasis mayor en aquellas relacionadas con la desarticulación de las carcasas: marcas transversales sobre las diáfisis proximales y distales de huesos largos y en sectores articulares del esqueleto axial, lo que es compatible con el aprovechamiento de animales de gran porte (Lyman, 1992). Asimismo, destacamos la presencia de marcas de corte longitudinales en las capas más antiguas (en las cuales el NISP de pinnípedos es relativamente mayor, pero el tamaño de estos es comparativamente menor), lo cual denotaría la mayor incidencia de prácticas de descarne. Lo dicho también es compatible con el tamaño de los animales, ya que trabajos antecedentes indican que las prácticas de fileteo dejarían más huellas en animales de dimensiones pequeñas (Lech et al., 2011). Es interesante destacar que el análisis del procesamiento de pingüinos ha mostrado una tendencia contraria, es decir, se observaron más procesados los restos óseos provenientes de los niveles superiores, en consonancia con una mayor abundancia de instrumental lítico (Horwitz y Weissel, 2011).

\section{Consideraciones finales}

La principal diferencia observada en las modalidades de explotación de pinnípedos entre los distintos niveles que conforman Bahía Crossley I fue la hallada en los perfiles de mortalidad, La cual puede ser interpretada como resultado de la puesta en práctica de distintas estrategias de aprovisionamiento. En trabajos previos, al promediar los restos óseos de todas las capas se sostuvo la posible explotación de apostaderos reproductivos, lo cual es 
coherente con la disponibilidad actual en la Isla de los Estados de tales espacios durante el verano (Martinoli, 2017). Sin embargo, al analizar cada uno de los niveles por separado es posible resaltar que mientras las capas VI y VII parecen indicar la captura de presas en sectores reproductivos, los perfiles de mortalidad de los niveles superiores son compatibles con el aprovechamiento de animales aislados y/o desagregados de los espacios de cría. Lo dicho puede implicar que las ocupaciones ocurrieron en distintos momentos del año. Sin embargo, para corroborar esta propuesta se debe conocer con precisión la estación de muerte de las presas, para lo cual es necesario el análisis de cortes delgados de dientes (Crespo, 1984; Schiavini, 1990). Respecto de los perfiles de mortalidad, también se destaca una tendencia temporal asociada a lo antes dicho: un aumento relativo en el tamaño de los pinnípedos seleccionados, lo que se da a partir de un consumo mayor de machos subadultos de 0 . flavescens. La otra diferencia que es posible resaltar se relaciona con la presencia de marcas de descarne/ fileteo en los restos óseos de otáridos provenientes de los niveles inferiores, lo que podría estar potencialmente relacionado con el menor tamaño promedio de los animales aprovechados (Lech et al., 2011, Lyman, 1992).

Si consideramos al sector sur del archipiélago fueguino como un espacio de circulación integrado de grupos marítimos (Horwitz, 1993, Zangrando, Panarello y Piana, 2014), las visitas a la Isla de los Estados podrían estar en consonancia con algunos de los procesos de cambio identificados en otros sectores del archipiélago. En primer lugar, las ocupaciones relevadas a partir de los conjuntos de los niveles VI y VII podrían estar potencialmente relacionados con el proceso de diversificación en la dieta observado en el canal Beagle hacia los 5000 años AP. Por un lado, a partir de ese período se observa una mayor presencia de presas alternativas a los pinnípedos (Zangrando, 2009). Por otro lado, hubo un aumento en el consumo de categorías de edad y sexo propias de espacios reproductivos (cachorros y hembras en edad reproductiva de $A$. australis), los cuales no se encuentran actualmente disponibles en el interior del canal Beagle (Martinoli, 2018, Martinoli y Vázquez, 2017, Zangrando et al. 2014), y dada la productividad primaria de dicho espacio posiblemente tampoco lo estuvieron en el pasado. Ahora bien, aunque para la región del canal Beagle el proceso de intensificación se propone para los 1500 años AP, basado en el mayor consumo de peces y aves pelágicos, los rangos de captura pueden haber comenzado a ampliarse en momentos previos (Tivoli y Zangrando, 2011). Incluso, algunos conjuntos de pinnípedos con fechados del Holoceno tardío indicaron una posible tendencia al procesamiento más intensivo (Martinoli, 2018, Martinoli y Vázquez, 2017), lo cual es compatible con un aumento en los costos de aprovisionamiento (Nagaoka, 2006).

Potencialmente, las primeras visitas documentadas para la Isla de los Estados (ca. 2700 años AP) podrían guardar relación con el aprovechamiento de los espacios reproductivos donde las presas se encuentran de manera agregada durante el verano. Posteriormente, y en concordancia con el aumento de las ocupaciones en la costa suroriental de Península Mitre (ca. 2400 años calibrados AP) (Zangrando et al., 2009), se observa un aumento en el tamaño de las presas seleccionadas en los niveles superiores de Bahía Crossley I. Lo dicho implica indirectamente que los perfiles de mortalidad dejan de reflejar el aprovechamiento directo de espacios reproductivos, pero también que comienzan a seleccionarse pinnípedos con un retorno energético mayor, a la vez que los pingüinos eran procesados más intensivamente. Esto podra asociarse con episodios de escasez de recursos en otros espacios del archipiélago (Horwitz y Weissel, 2011), en la medida en que parece comenzar un aumento demográfico, que es lo que posiblemente refleja el proceso de intensificación acontecido alrededor de los 1500 años AP (Zangrando, 2009).

Ushuaia, 31 de mayo de 2019

\section{Agradecimiento}

Este trabajo está dedicado a la memoria de la Dra. Victoria Horwitz, quien generosamente compartió todos los documentos que había generado en el marco de la excavación de Bahía Crossley I y fue pionera en los trabajos allí realizados. Agradezco a Francisco Zangrando por las lecturas del manuscrito. Este trabajo se realizó en el marco del PICT 1230-2017.

\section{Bibliografía}

Acha, E., Mianzan, H., Guerrero, R., Favero, M. y Bava, J. (2004). Marine fronts at the continental shelves of austral South America: physical and ecological processes. Journal of Marine Systems, 44(1), 83-105.

Bastida, R. y Rodríguez, D. (2003). Mamíferos Marinos de Patagonia y Antártida. Buenos Aires: Vázquez Mazzini Editores.

Behrensmeyer, A. (1978). Taphonomic and Ecologic Information from Bone Weathering. Paleobiology, 5, 150-162.

Binford, L. (1978). Nunamiut Ethnoarchaeology. Nueva York: Academic Press.

Binford, L. (1981). Bones: Ancient Men and Modern Myths. Nueva York: Academic Press.

Borella, F. (2003). Revisión de los restos de cetáceos recuperados en el sitio Bahía Crossley I, Isla de los Estados (Argentina). Evidencia de consumo y utilización como 
materia prima. Magallania, 31, 61-68.

Borella, F. (2004). Tafonomía regional y estudios arqueofaunísticos de cetáceos en Tierra del Fuego y Patagonia meridional (Vol. 1257). Oxford: BAR.

Borella, F. (2006). ¿Dónde están los lobos en la costa atlántica de norpatagonia? Explorando vías para resolver el registro arqueofaunístico. Werken, 9, 97-114.

Borella, F., Grandi, F., Vales, D., Goodall, N. y Crespo E. (2013). Esquema preliminar de fusión epifisaria en huesos de lobos marinos (Arctocephalus australis y Otaria flavescens), su contribución en los análisis zooarqueológicos. En F. Zangrando, R. Barberena, A. Gil, G. Neme, M. Giardina, L. Luna, C. Otaola, S. Paulides, L. Salgán y A. Tivoli (eds.), Tendencias teóricometodológicas y casos de estudio en la arqueología de Patagonia (pp. 39-51). San Rafael: Museo de Historia Natural.

Borella, F., Gutiérrez, M., Fodere, H. y Merlo, J. (2007). Estudio de densidad mineral ósea para dos especies de otáridos frecuentes en el registro arqueofaunístico patagónico (Otaria flavescens y Arctocephalus australis). En F. Morello, A. Prieto, M. Martinic y G. Bahamonde (eds.), Arqueología de Fuego-Patagonia. Levantando Piedras, Desenterrando Huesos y Develando Arcanos (pp. 421-426). Punta Arenas: Ediciones CEQUA.

Borella, F., Vales, D., Grandi, F. y García N. (2018). Rasgos diagnósticos en elementos postcraneales de dos especies de otáridos para su identificación en el registro zooarqueológico. Magallania, 46(2), 187-203.

Cadegán Sepúlveda, K. (2013). Anatomía comparada del esqueleto apendicular de dos especies de otáridos, Otaria flavescens (Shaw, 1800) Arctophoca australis gracilis (Zimmerman, 1783) (tesis de grado). Universidad Austral de Chile, Chile.

Cartajena, I. F. y Labarca, R. (2007). Patrones Históricos de Cuereo en Lobos Marinos: La Evidencia de los Abrigos 1 y 2 de Playa Yámana (Isla Livingston, Antártica Chilena). Magallania, 35(1), 95-105.

Chapman, A. (1987). Isla de los Estados en la Prehistoria: Primeros Datos Arqueológicos. Buenos Aires: Eudeba.

Crespo, E. (1984). Dimorfismo sexual en los dientes caninos y en los cráneos de lobo marino del sur, Otaria flavescens (Shaw) (Pinnipedia, Otariidae). Revista del Museo Argentino de Ciencias Naturales e Instituto Nacional de Investigación de las Ciencias Naturales, 13, 245-254.

Crespo, E., Schiavini, A., García, N., Franco-Trecu, V., Goodall, N., Rodríguez, D., Morgante, J. y Oliveira, L.
(2015). Status, population trend and genetic structure of South American fur seals, Arctocephalus australis, in southwestern Atlantic waters. Marine Mammal Science, 31(3), 866-890.

Etnier, M. (2007). Defining and identifying sustainable harvests of resources: Archaeological examples of pinniped harvests in the eastern North Pacific. Journal for Nature Conservation, 15(3), 196-207.

Grayson, D. (1984). Quantitative Zooarchaeology. Nueva York: Academic Press.

Horwitz, V. (1990). Maritime settlement patterns in Southeastern Tierra del Fuego (Argentina) (tesis doctoral). University of Kentucky, Kentucky.

Horwitz, V. (1993). Maritime Settlement Patterns: Isla de los Estados. En J. Lanata (ed.), Explotación de Recursos Faunísticos en Sistemas Adaptativos Americanos, Arqueología Contemporánea 4 (pp. 149-161). Estados Unidos.

Horwitz, V. y Weissel, M. (2011). Arqueología de Isla de los Estados: La frontera de la abundancia. En F. Zangrando, M. Vázquez y A. Tessone (eds.), Los cazadores recolectores del extremo oriental fueguino. Arqueología de Península Mitre e Isla de los Estados (pp. 143-170). Buenos Aires: Sociedad Argentina de Antropología.

King, J. (1983). Seals of the world. Londres: Oxford University Press.

Lanata, J., Weissel, M., Caracotche, M., Belardi, J., Muñoz, S. y Savanti, F. (1992). Dos mil huesos de viaje submarino: análisis faunístico del sitio Bahía Crossley 1, Isla de los Estados. Palimpsesto. Revista de Arqueología, 1, 9-24.

Lech, V., Betts, M y Maschner, H. (2011). An analysis of seal, sea lion, and sea otter consumption patterns on Sanak Island, Alaska: a 4500 year record on Aleut consumer behaviour. En T. Braje y T. Rick (eds.), Human Impacts on Seals, Sea Lions, and Sea Otters: Integrating Archaeology and Ecology in the Northeast Pacific (pp. 111-128). California: University of California Press.

Legoupil, D. (1989). La identificación de los mamíferos marinos en los sitios canoeros de Patagonia: problema y constataciones. Anales del Instituto de la Patagonia, 19, 101-113.

L'Heureux, G. y Borella, F. (2011). Guía Osteométrica para el estudio de elementos óseos de Otaria flavescens. Buenos Aires: Universidad Nacional del Centro de la Provincia de Buenos Aires.

Lyman, R. (1989). Seal and Sea-lion Hunting: A Zooarchaeological Study from the Southern Northwest 
Coast of North America. Journal of Anthropological Archaeology, 8, 68-99.

Lyman, R. (1992). Prehistoric Seal and Sea-lion Butchering on the Southern Northwest Coast. American Antiquity, 57(2), 246-261.

Lyman, R. (1994). Vertebrate Taphonomy. Cambridge: Cambridge University Press.

Lyman, R. (2003). Pinniped behavior, foraging theory, and the depression of metapopulations and nondepression of a local population on the southern Northwest Coast of North America. Journal of Anthropological Archaeology, 22, 376-388.

Martinoli, M. (2017). Pautas de procesamiento y consumo de pinnípedos en la costa sur de Tierra del Fuego e Isla de los Estados: un análisis comparativo. Arqueología, 23(3), 173-196.

Martinoli, M. (2018). Modalidades de explotación, procesamiento y consumo de pinnípedos en la margen meridional de Tierra del Fuego (tesis doctorado). Facultad de Filosofía y Letras, Universidad de Buenos Aires, Buenos Aires.

Martinoli, M. y Vázquez, M. (2017). Pinniped Capture and Processing: a Comparative Analysis from Beagle Channel (Tierra del Fuego, Argentina). En M. Mondini, S. Muñoz y P. Fernández (eds.), Zooarchaeology in the Neotropics: Environmental Diversity and Human-Animal Interactions (pp. 7-23). Nueva York: Springer.

Muñoz, S. (1996). Explotación de pinnípedos en la costa Atlántica de Tierra del Fuego. Arqueología, 6, 199-222.

Muñoz, S. (2005). Current perspectives on human-animal relationships in Atlantic Tierra del Fuego island, southern Patagonia. Before Farming, 2, 183-196.

Muñoz, S. (2014). La explotación de lobos marinos por cazadores-recolectores terrestres de Tierra del Fuego. En J. Oría y A. Tivoli (eds.), Cazadores de mar y tierra. Estudios recientes en arqueología fueguina (pp. 197218). Ushuaia: Museo del Fin del Mundo.

Nagaoka, L. (2006). Prehistoric seal carcass exploitation at the Shag Mouth site, New Zealand. Journal of Archaeological Science, 33, 1474-1481.

Orquera, L. y Piana, E. (1999). Arqueología de la región del canal Beagle (Tierra del Fuego, Argentina). Buenos Aires: Sociedad Argentina de Antropología.

Orquera, L. y Piana, E. (2009). Sea Nomads of the Beagle Channel in Southernmost South America: Over Six Thousand Years of Coastal Adaptation and Stability.
Journal of Island \& Coastal Archaeology, 4, 61-81.

Pérez García, M. (2003). Osteología comparada del esqueleto postcraneano de dos géneros de otariidae del Uruguay. Boletín de la Sociedad Zoológica del Uruguay, $14,1-16$.

Pérez García, M. (2008). Ontogenia del postcráneo de Arctocephalus australis (mammalia, carnivore, otariidae). Boletín de la Sociedad Zoológica del Uruguay, 17, 1-19.

Ponce, J. (2009). Palinología y geomorfología del Cenozoico tardío de la lsla de los Estados (tesis doctoral). Universidad Nacional del Sur, Bahía Blanca.

Rabassa, J., Bujalesky, G., Meglioli, A., Coronato, A., Gordillo, S., Roig, C. y Salemme, M. (1992). The Quaternary of Tierra del Fuego, Argentina: the status of our knowledge. SGU series Ca. Research Paper, 81, 249-256.

San Román, M. (2009). Anatomía económica de Otaria flavescens. En P. López, I. Cartajena, C. García y F. Mena (eds.), Zooarqueología en el confín del mundo (pp. 169-180). Santiago de Chile: Facultad de Estudios del Patrimonio Cultural de la Universidad Internacional SEKChile, Área de arqueología.

Schiavini, A. (1990). Estudio de la relación entre el hombre y los pinnípedos en el proceso adaptativo humano del canal Beagle (Tierra del Fuego, Argentina) (tesis doctorado). Facultad de Ciencias Exactas y Naturales, Universidad de Buenos Aires, Buenos Aires.

Schiavini, A., Crespo, E. y Szapkievich, V. (2004). Status of the population of South American sea lion (Otaria flavescens Shaw, 1800) in southern Argentina. Mammalian Biology-Zeitschrift für Säugetierkunde, 69(2), 108-118.

Schiavini, A. y Raya Rey, A. (2001). Aves y Mamíferos Marinos en Tierra del Fuego. Estado de situación, interacción con actividades humanas y recomendaciones para su manejo. Informe preparado bajo contrato con el proyecto "Consolidación e Implementación del Plan de Manejo de la Zona costera Patagónica", proyecto ARG/97/ G31 GEF/PNUD/MRECIC CADIC-CONICET.

Sielfeld, W. (1983). Mamíferos Marinos de Chile. Santiago: Ediciones de la Universidad de Chile.

Smith, I. (1978). Seasonal sea mammal exploitation and butchering patterns in an archaic site (Tairua, N44/2) on the Coromandel Peninsula. Records of the Auckland Institute and Museum, 17-26.

Tivoli, A., y Zangrando, A. (2011). Subsistence variations and landscape use among maritime hunter-gatherers. 
A zooarchaeological analysis from the Beagle Channel (Tierra del Fuego, Argentina). Journal of Archaeological Science, 38(5), 1148-1156.

Vaz Ferreira, R. (1979). South American sea lion. FAO Fisheries Series, 5(2), 9-12.

Vaz Ferreira, R. (1981). South American sea lion Otaria flavescens (Shaw 1800). En S. Ridgway y R. Harrison (eds.), Handbook of Marine Mammals (pp. 39-65). Cambridge: Academic Press.

Vaz Ferreira, R. y Vallejo, S. (1981). Algunos aspectos del comportamiento de Arctocephalus australis (Zimmerman) lobo de dos pelos de Sudamérica (pinnipedia-otariidae) en el Uruguay. En VI Jornadas Argentinas de Zoología, Simposios: 223- 236. La Plata.

Zangrando, F. (2009). Historia evolutiva y subsistencia de cazadores-recolectores marítimos de Tierra del Fuego. Buenos Aires: Sociedad Argentina de Antropología.
Zangrando, F., Panarello, H. y Piana, E. (2014). Zooarchaeological and stable isotopic assessments on pinniped-human relations in the Beagle Channel (Tierra del Fuego, southern South America). International Journal of Osteoarchaeology, 24(2), 231-244.

Zangrando, F., Tessone, A. y Vázquez, M. (2009). El uso de espacios marginales en el archipiélago fueguino: implicaciones de la evidencia arqueológica de Bahía Valentín. En M. Salemme, F. Santiago, M. Álvarez, E. Piana, M. Vázquez y E. Mansur (eds.), Arqueología de Patagonia: una Mirada desde el Último Confín, (pp. 4762). Ushuaia: Utopías.

Zangrando, F., Vázquez, M., Tessone, A., Tivoli, A., Martinoli, M., Fernández Ropero, C., Alunni, D. y Pinto Vargas, G. (2017). Primeros datos sobre la arqueología de bahía Franklin, Isla de los Estados. X Jornadas de Arqueología de la Patagonia (31 de Julio al 5 de agosto). Puerto Madryn: CENPAT. 